\title{
Investigation of electron beam lithography effects on metal-insulator transition behavior of vanadium dioxide
}

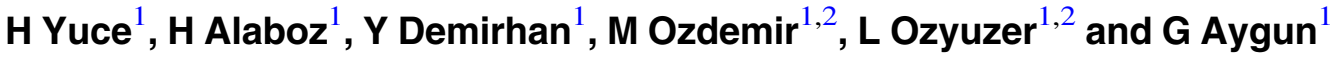 \\ ${ }^{1}$ Department of Physics, Izmir Institute of Technology, 35430 Urla, Izmir, Turkey \\ ${ }^{2}$ Teknoma Technological Materials Ltd, 35430 Urla, Izmir, Turkey \\ E-mail: ozyuzer@iyte.edu.tr
}

Received 26 April 2017, revised 25 September 2017

Accepted for publication 3 October 2017

Published 25 October 2017

\begin{abstract}
Vanadium dioxide $\left(\mathrm{VO}_{2}\right)$ shows metal-insulator phase transition at nearly $68^{\circ} \mathrm{C}$. This metalinsulator transition (MIT) in $\mathrm{VO}_{2}$ leads to a significant change in near-infrared transmittance and an abrupt change in the resistivity of $\mathrm{VO}_{2}$. Due to these characteristics, $\mathrm{VO}_{2}$ plays an important role on optic and electronic devices, such as thermochromic windows, meta-materials with tunable frequency, uncooled bolometers and switching devices. In this work, $\mathrm{VO}_{2}$ thin films were fabricated by reactive direct current magnetron sputtering in $\mathrm{O}_{2} / \mathrm{Ar}$ atmosphere on sapphire substrates without any further post annealing processes. The effect of sputtering parameters on optical characteristics and structural properties of grown thin films was investigated by SEM, XRD, Raman and UV/VIS spectrophotometer measurements. Patterning process of $\mathrm{VO}_{2}$ thin films was realized by e-beam lithography technique to monitor the temperature dependent electrical characterization. Electrical properties of $\mathrm{VO}_{2}$ samples were characterized using microprobe station in a vacuum system. MIT with hysteresis behavior was observed for the unpatterned square samples at around $68^{\circ} \mathrm{C}$. By four orders of magnitude of resistivity change was measured for the deposited $\mathrm{VO}_{2}$ thin films at transition temperature. After e-beam lithography process, substantial results in patterned $\mathrm{VO}_{2}$ thin films were observed. In this stage, for patterned $\mathrm{VO}_{2}$ thin films as stripes, the change in resistivity of $\mathrm{VO}_{2}$ was reduced by a factor of 10 . As a consequence of electrical resistivity measurements, MIT temperature was shifted from $68^{\circ} \mathrm{C}$ to $50{ }^{\circ} \mathrm{C}$. The influence of e-beam process on the properties of $\mathrm{VO}_{2}$ thin films and the mechanism of the effects are discussed. The presented results contribute to the achievement of $\mathrm{VO}_{2}$ based thermochromic windows and bolometer applications.
\end{abstract}

Keywords: vanadium dioxide, metal insulator transition, e-beam lithography, magnetron sputtering

(Some figures may appear in colour only in the online journal)

\section{Introduction}

Transition metal oxides have been investigated widely due to their peculiar electrical and optical properties. Vanadium dioxide $\left(\mathrm{VO}_{2}\right)$ indicates a reversible metal insulator transition (MIT) at $\sim 68{ }^{\circ} \mathrm{C}[1,2]$. It has been reported that MIT behavior of $\mathrm{VO}_{2}$ strongly varied in wide range with crystal quality, grain size, grain boundaries and defects related to self-doping and the other factors $[3,4]$. While $\mathrm{VO}_{2}$ has monoclinic crystal structure with insulator phase at below the MIT temperature
$\left(T_{\mathrm{MIT}}\right)$, the material has tetragonal rutile crystal structure with metallic phase at above $T_{\mathrm{MIT}}[5,6]$. During the transition, the change in the volume of $\mathrm{VO}_{2}$ crystal is around $1 \%-2 \%$ [7]. In insulator phase, the energy bandgap of $\mathrm{VO}_{2}$ is around $0.65 \mathrm{eV}$ [8]. There have been two views on the origin of MIT in $\mathrm{VO}_{2}$; Peierles transition and Mott-Hubbard transition. Peierles transition arises due to the change in crystal structure, and Mott-Hubbard transition takes places due to electron-electron correlations [9]. MIT in $\mathrm{VO}_{2}$ can be induced by heating [10], doping [11, 12], ion bombardment [13] and UV light [14]. 
Table 1. Deposition parameters and morphology of $\mathrm{VO}_{2}$ samples.

\begin{tabular}{lcclll}
\hline Sample & Reactive oxygen ratio (\%) & Deposition time (min) & Average grain size (nm) & Thickness (nm) & Electrical properties \\
\hline A & 2.00 & 45 & NA & 310 & MIT \\
B & 2.00 & 22.5 & $<20$ & 120 & Non-transition (metallic) \\
C & 2.25 & 22.5 & NA & 125 & MIT \\
D & 2.50 & 22.5 & 150 & 124 & Non-transition (insulator) \\
E & 3.00 & 22.5 & 150 & 127 & Non-transition (insulator) \\
\hline
\end{tabular}

Insulator $\mathrm{VO}_{2}$ has high transmittance whereas metallic $\mathrm{VO}_{2}$ becomes opaque to near-IR radiation [15, 16]. MIT behavior of $\mathrm{VO}_{2}$ is not only accompanied by significant change in infrared transmittance but also sharp change in resistivity. The transition takes place in approximately $80 \mathrm{fs}$, which is useful property for switching applications [17]. Moreover, MIT in $\mathrm{VO}_{2}$ exhibits hysteresis behavior which can be tuned. These characteristics can be useful in many areas of optics and electronics, such as thermochromic windows [18, 19], tunable frequency meta-materials [20], detectors [21-24] and switching devices $[25,26]$. Sensor applications require negligible hysteresis with high resistance drop during phase transition while the storage type devices require relatively large hysteresis [27].

There are various techniques to fabricate $\mathrm{VO}_{2}$ films, such as pulsed laser deposition [28], chemical vapor deposition [29], atomic layer deposition [30], spray pyrolysis [31] thermal oxidation [32], sol-gel method [33] and magnetron sputtering $[34,35]$. Being the most suitable technique in terms of large area growth, uniform deposition and high crystal quality [36], magnetron sputtering technique has advantageous in many respects to the others techniques.

Since it has been a challenging task to grow high quality $\mathrm{VO}_{2}$ thin films, various substrates have been used as seen from the literature $[15,37]$. The microstructure of deposited $\mathrm{VO}_{2}$ thin films depends on lattice matching and surface energy of the substrates. Although silicon substrates are relatively cheaper and widely used in microelectronics, it is quite challenging to deposit high quality $\mathrm{VO}_{2}$ films due to unavailability of its native oxide layer on the silicon substrates [37]. However, the sapphire substrates are commonly used for achieving high quality $\mathrm{VO}_{2}$ thin films due to the fact that it has high thermal conductivity compared to the other ones.

In this study, $\mathrm{VO}_{2}$ thin films were successfully grown on c-cut sapphire without any post annealing processes. The structural, optical and electrical properties of these grown thin films were investigated. The grown $\mathrm{VO}_{2}$ films were patterned by e-beam lithography for the electrical measurements. The effect of structure size, patterning process on resistivity and MIT characteristics of $\mathrm{VO}_{2}$ thin film were investigated. It is observed that e-beam patterned stripes with narrowed width (e.g. high aspect ratio ranging from 44 to 220) have peculiar properties. These will be discussed in detail in results and discussion part. The main outcome of this study is highly important that $T_{\mathrm{MIT}}$ was decreased from $68{ }^{\circ} \mathrm{C}$ to $50{ }^{\circ} \mathrm{C}$ as a result of e-beam lithography processing.

\section{Experimental procedure}

$\mathrm{VO}_{2}$ thin films were deposited on c-cut sapphire $\left(\mathrm{Al}_{2} \mathrm{O}_{3}\right.$ (0001)) using high purity $(99.95 \%)$ vanadium (V) target by DC magnetron sputtering technique [38, 39]. Substrates were cleaned with acetone and DI water by means of ultrasonic cleaner. The vacuum chamber was evacuated to a base pressure of $1.2 \times 10^{-6}$ mbar and the substrate was kept at $550{ }^{\circ} \mathrm{C}$ during deposition. In order to get rid of any contaminations of target's surface, $10 \mathrm{~min}$ pre-sputtering was performed on the target prior to deposition. $\mathrm{VO}_{2}$ thin films were grown under $8.5 \times 10^{-3}$ mbar of $\mathrm{O}_{2}$ and $\mathrm{Ar}$ mixed gas pressure environment and $50 \mathrm{~W}$ of sputtering power. The substrates were rotated at $15 \mathrm{rpm}$ in order to improve the uniformity of the film during the deposition process. Oxygen gas ratio of the sputtered thin films was varied in order to investigate the growth conditions of $\mathrm{VO}_{2}$ thin films having sharp resistivity changes at $T_{\mathrm{MIT}}$. Sample deposition parameters and the properties of the discussed films can be seen in table 1. In our experiments, firstly $310 \mathrm{~nm} \mathrm{VO}_{2}$ (named sample A) was grown on sapphire substrate during $45 \mathrm{~min}$. According to analysis results, high quality $\mathrm{VO}_{2}$ with the high change in resistivity depending on the temperature was observed. After that, in order to obtain thinner $\mathrm{VO}_{2}$ film, we reduced deposition time from 45 to $22.5 \mathrm{~min}$. Therefore, we obtained $125 \mathrm{~nm}$ vanadium oxide thin films with various unexpected phase at different oxygen concentrations. According to optimized parameters of the sample A, deposition time was reduced to $22.5 \mathrm{~min}$ at the same oxygen concentration $(2.00 \%)$, and we deposited $125 \mathrm{~nm} \mathrm{VO}_{x}$ with $2.00 \%$ oxygen rate (named sample B). For sample B, MIT was not observed. Due to that, oxygen concentration was increased up to $3.00 \%$ (named sample $\mathrm{C}$ for $2.25 \% \mathrm{O}_{2}$, sample $\mathrm{D}$ for $2.50 \% \mathrm{O}_{2}$, sample $\mathrm{E}$ for $\% 3.00 \mathrm{O}_{2}$ ) with $22.5 \mathrm{~min}$ deposition time. However, for $125 \mathrm{~nm} \mathrm{VO}_{x}$ thin films, high quality $\mathrm{VO}_{2}$ thin film like sample A could not be obtained. $125 \mathrm{~nm}$ grown $\mathrm{VO}_{x}$ thin films except sample $\mathrm{C}$ did not exhibit MIT. As considering all grown films, only sample $\mathrm{A}$ and sample $\mathrm{C}$ show a transition. When especially electrical analysis results were examined, it is clear that sample A is more quality with high changing resistivity rate than sample C.

Structural and morphological properties of the films were characterized by field emission scanning electron microscopy (FE-SEM, Philips Quanta) equipped with energy dispersive spectroscopy (EDS, Oxford X-act). X-ray diffractometry (XRD, Philips PANanalytical X'Pert System) was used for the structural properties of the grown $\mathrm{VO}_{2}$ thin films. The 


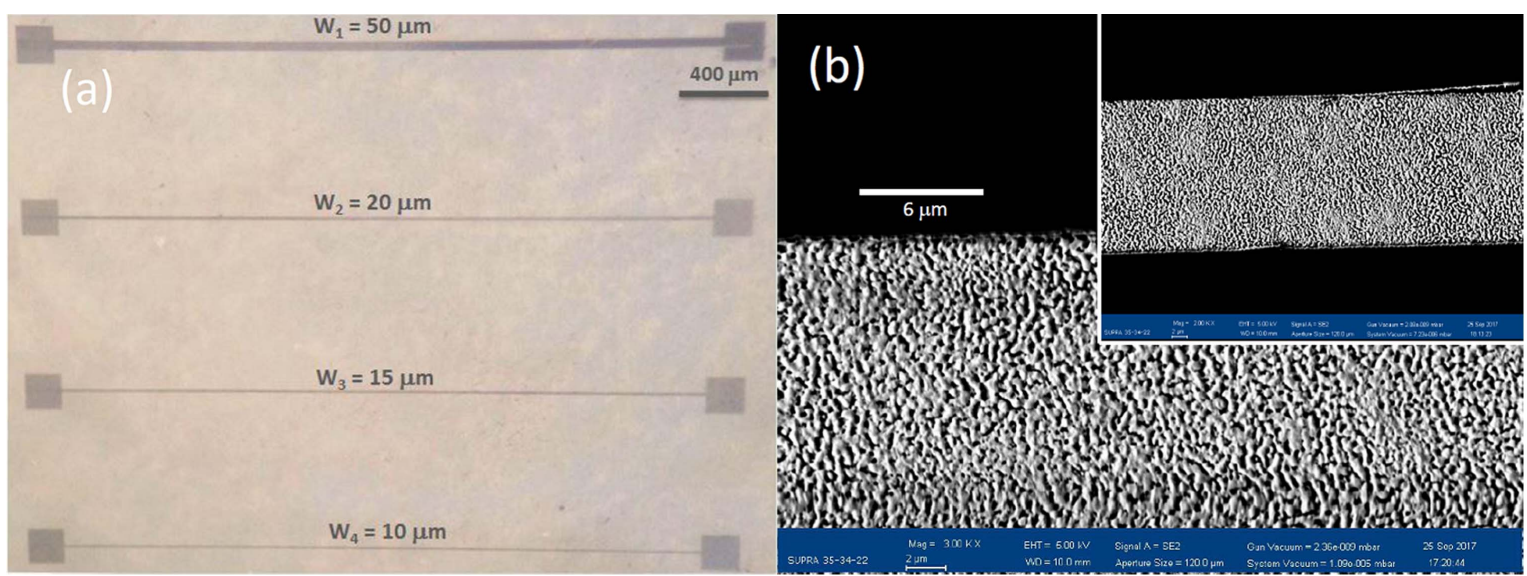

Figure 1. In order to investigate e-beam effect on $\mathrm{VO}_{2}$ thin films, the $\mathrm{VO}_{2}$ strips with varied dimensions were designed and fabricated. (a) The optical image of e-beam patterned $\mathrm{VO}_{2}$ thin film (sample A, $310 \mathrm{~nm}$ thickness) strips with 50, 20, 15 and $10 \mu \mathrm{m}$ strip widths (W) and $2.2 \mathrm{~mm}$ strip length is given. (b) SEM image of $20 \mu \mathrm{m}$ width strip edge. The black region is sapphire. The inset shows the full width of the strip which corresponds to $20 \mu \mathrm{m}$.
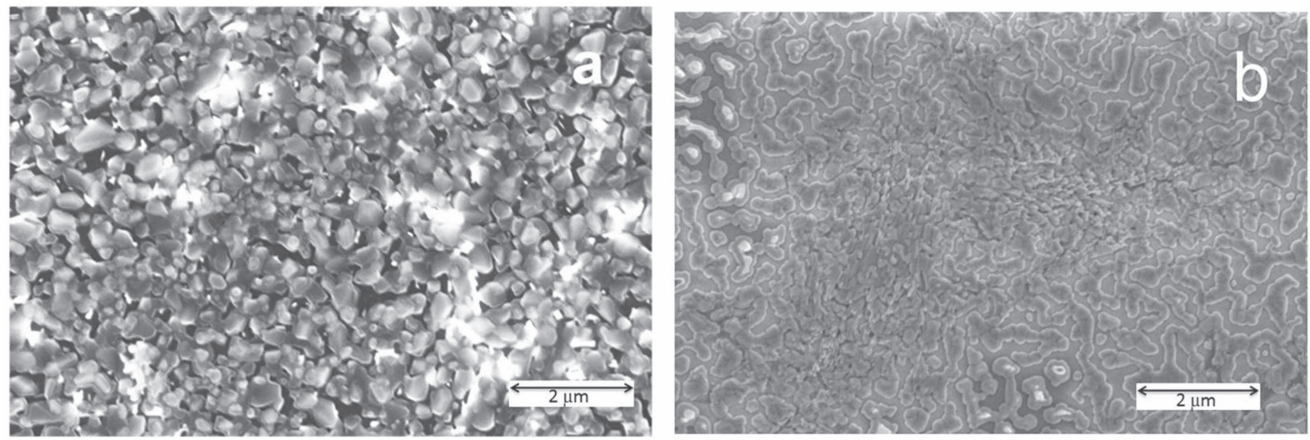

Figure 2. Field emission scanning electron microscope (SEM) images of $310 \mathrm{~nm} \mathrm{VO}_{2}$ thin film (sample A) (a) and $125 \mathrm{~nm} \mathrm{VO}_{2}$ thin film (sample C) (b) with $2 \mu \mathrm{m}$ length scale bars. (Among all grown vanadium oxide thin films given in table 1, sample A and sample C have both shown MIT.)

XRD measurements were performed from $10^{\circ}$ to $80^{\circ}$ for $2 \theta$ using $\mathrm{Cu} K_{\alpha}$ radiation $(\lambda=1.5406 \AA)$ with step size of $0.04^{\circ}$ and time step of $1 \mathrm{~s}$. Optical transmittance spectra of samples at normal incidence were taken between 200 and $1200 \mathrm{~nm}$ using spectrophotometer (UV/VIS Spectrophotometer, Perkin Elmer) with a precisely controlled homemade heating mechanism. The thickness of the grown thin films was measured by a surface profilometer (Veeco DEKTAK 150). Raman measurements were taken by a confocal Raman spectroscopy (Scientific Instruments). The resolution of the Raman measurements was $2.0 \mathrm{~cm}^{-1}$. Argon laser with 514 and $633 \mathrm{~nm}$ excitation wavelengths having $120 \mathrm{~mW}(514 \mathrm{~nm}$ laser) and $20 \mathrm{~mW}$ (633 nm laser) power were used for the Raman analysis.

Deposited high quality $\mathrm{VO}_{2}$ thin films were patterned by e-beam lithography (Raith e-line e-beam lithography system) to investigate the effects of e-beam on MIT characteristics of aforementioned films. For this purpose, the $\mathrm{VO}_{2}$ films were coated with AZ5214 photoresist at $3000 \mathrm{rpm}$ for $50 \mathrm{~s}$. Photoresist coated films were heat treated for $30 \mathrm{~min}$ in a furnace kept at $90{ }^{\circ} \mathrm{C}$. After the film was patterned by e-beam, it was exposed to ultraviolet light (OAI Mask Aligner) for $7 \mathrm{~s}$. Later, it was put in developer solution and rinsed with deionized water. Followed by hard bake process at $120{ }^{\circ} \mathrm{C}$, $\mathrm{Ar}$ ion milling was performed. The samples were water cooled during etching of $\mathrm{VO}_{2}$ to create strips. Remaining photoresist was stripped away with acetone at the last step of the patterning process [40, 41]. Final structure of shaped $\mathrm{VO}_{2}$ stripes and a representative SEM picture were given in figure 1 . The discussion of the images were deferred to a later part of this paper.

Electrical measurements of $\mathrm{VO}_{2}$ samples were done between $30{ }^{\circ} \mathrm{C}$ and $100{ }^{\circ} \mathrm{C}$ with usage of microprobe station (Janis Microprobe Station). A Labview controlled computer program was used to record the measurements done by a Keithley sourcemeter.

\section{Results and discussions}

\subsection{Structural properties}

Surface morphologies of the grown $\mathrm{VO}_{2}$ thin films having different $\mathrm{O}_{2} / \mathrm{Ar}$ flow rates and deposition durations were investigated using SEM (figure 2). There are many variables such as substrate, growth temperature, deposition rate and sputtered ion energy affecting the quality of the grown vanadium oxide films. In this study, we investigated two 

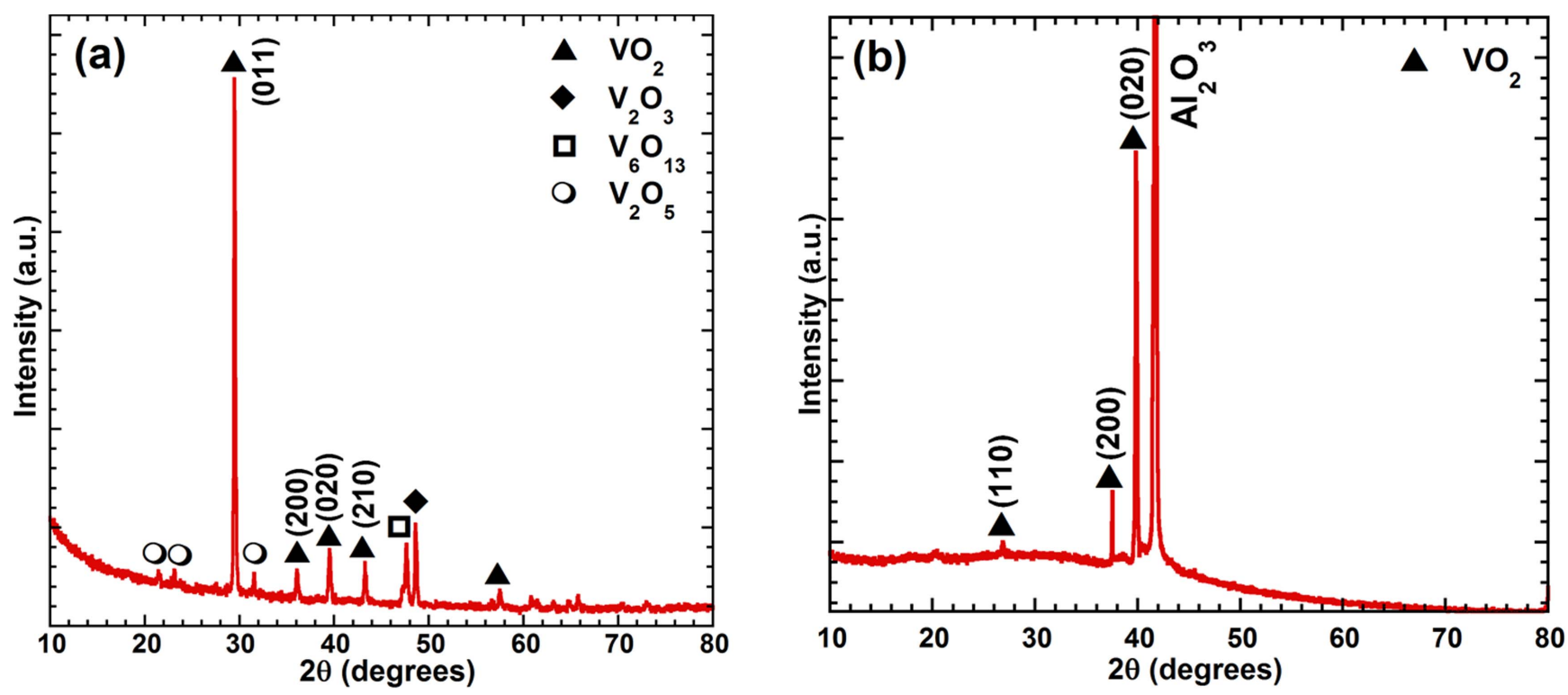

Figure 3. XRD spectrum of sample A (a) and sample C (b) which shows MIT behavior. Here, it is seen that sample A $-310 \mathrm{~nm}$ film thickness with $2.00 \%$ oxygen concentration- exhibits high intensity $\mathrm{VO}_{2}$ diffraction peak. However, XRD diffraction peaks of sample $\mathrm{C}$ $-125 \mathrm{~nm}$ film thickness with $2.25 \%$ oxygen concentration-belong to $\mathrm{VO}_{2}$ are at lower intensity.

parameters, namely oxygen concentration in grown vanadium oxide films and the thickness of the films. These two variables in our experiments affect grain size and surface morphology of the thin films. As shown in table 1, sample A and C exhibit MIT among deposited thin films.

Figure 2 shows SEM images of samples A and C. While sample A has small grains (figure 2(a)), sample $\mathrm{C}$ has meander like structure (figure 2(b)). It is concluded that increasing deposition time and decreasing oxygen concentration of the films convert meander like grains to small grains. This effect can be explained with the diffusion and migration of adsorbed atoms; increasing deposition time gives additional time to adatoms for diffusion and migration on the substrate surface which is essential for nucleation and growth [42].

The XRD patterns of as grown thin films at different $\mathrm{O}_{2}$ flow rates and growth duration were collected for $2 \theta$ between $10^{\circ}$ and $80^{\circ}$. There are two important peaks observed at $\sim 29^{\circ}$ and $39^{\circ}$ related to $\mathrm{VO}_{2}$ as seen in figure 3 (a). These can be assigned to (011) and (020) diffraction peaks [42]. Since the film is quite thin for sample $\mathrm{C}$, a strong peak at $2 \theta \sim 41^{\circ}$ is detected belonging to sapphire substrate [43] as shown in figure 3(b). According to XRD results, the films consist of mixed phases, i.e. $\mathrm{VO}_{2}, \mathrm{~V}_{2} \mathrm{O}_{3}, \mathrm{~V}_{2} \mathrm{O}_{5}$ and $\mathrm{V}_{6} \mathrm{O}_{13}[43,44]$. It can be understood from the XRD peaks that $2.00 \%$ oxygen to argon ratio is a reasonable choice to grow $310 \mathrm{~nm}$ thick vanadium oxide films in the form of mainly $\mathrm{VO}_{2}$ phase. In addition, in case of thickening the grown film, the orientation of vanadium oxide crystal changes compared to substrate orientation, and this leads to consist of more polycrystalline structure as in sample A. Due to the change in crystal orientation depending on the film thickness, the peaks which are the highest intensity belong to sample $\mathrm{A}$ and $\mathrm{C}$ are different from each other.

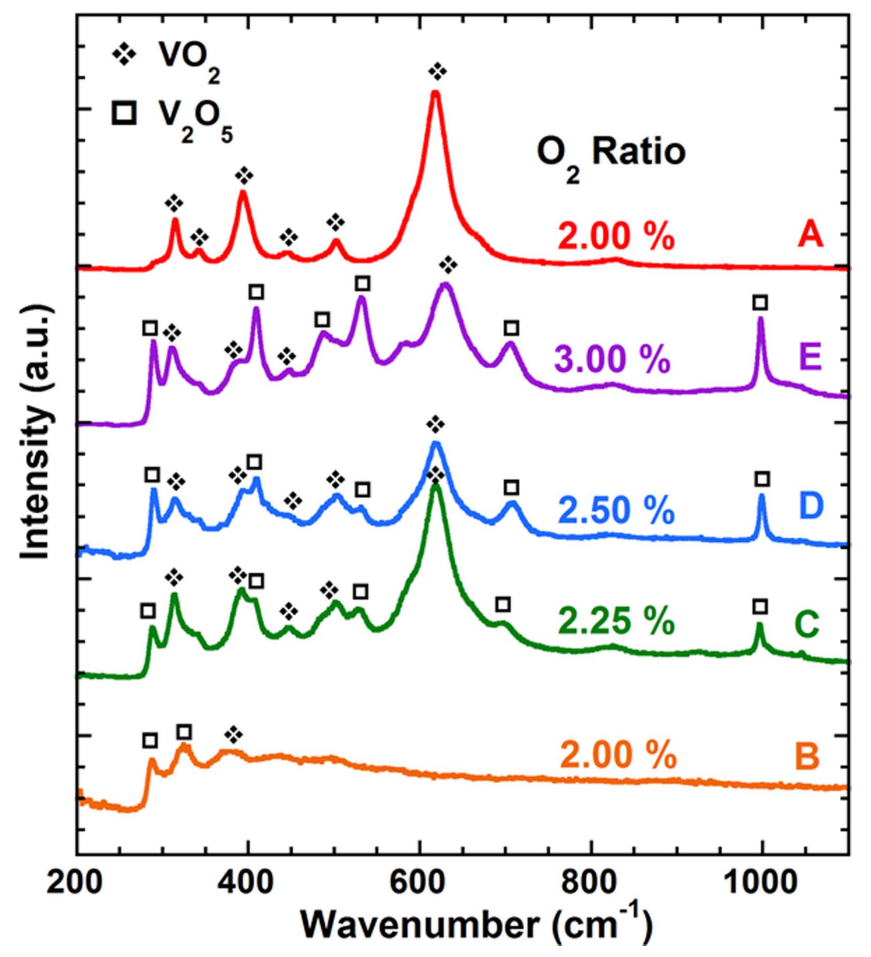

Figure 4. Raman spectra of thin films deposited at different $\mathrm{O}_{2} / \mathrm{Ar}$ flow ratios. Note that sample $A$ is thicker than the rest of the samples. According to the Raman spectra of sample A and sample B, main observed vanadium oxide Raman modes are disappeared with decreasing film thickness. Also, in case of decreasing $\mathrm{O}_{2} / \mathrm{Ar}$ flow ratio, the grown vanadium oxide thin films with the same thickness (sample B, C, D and E) exhibit more metallic properties.

Raman microscopy analyses were carried out at room temperature for each sample in order to investigate the oxygen flow ratio effects on the phases of vanadium oxide films (figure 4). In order to prevent phase transition due to heating effects during the measurement, laser intensity was 


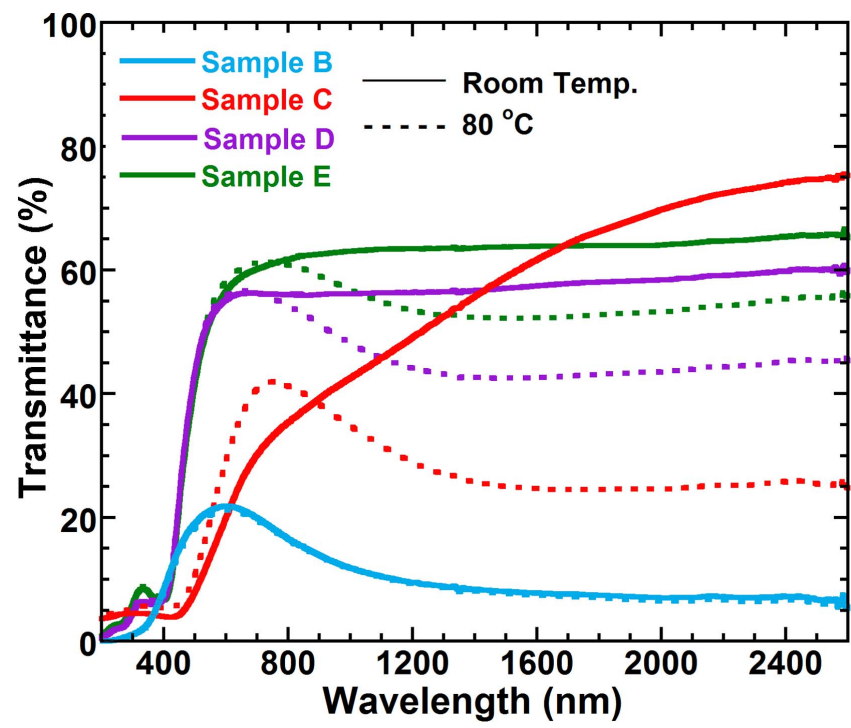

Figure 5. Optical properties of deposited $\mathrm{VO}_{2}$ thin films with different oxygen flow ratios at room and above transition temperatures. Note that solid lines correspond to room temperature measurement and dashed lines for $80{ }^{\circ} \mathrm{C}$ ones.

minimized to its lowest possible value. Raman analysis show that $\mathrm{VO}_{2}$ and $\mathrm{V}_{2} \mathrm{O}_{5}$ coexist in grown thin films except for sample A. Raman peaks detected at 313, 342, 392, 445, 502 and $617 \mathrm{~cm}^{-1}$ correspond to $\mathrm{VO}_{2}$ phase as reported in the literature [45]. The main $\mathrm{V}-\mathrm{V}$ band at $617 \mathrm{~cm}^{-1}$ belongs to $\mathrm{VO}_{2}$ phase. Besides $\mathrm{VO}_{2}$ peaks, the detected signals at 288 , $408,488,530,704$ and $997 \mathrm{~cm}^{-1}$ correspond to $\mathrm{V}_{2} \mathrm{O}_{5}$ characteristic peaks [46]. The highest Raman intensities belonging to $\mathrm{VO}_{2}$ phase with a lower $\mathrm{V}_{2} \mathrm{O}_{5}$ intensity mode are detected for sample $\mathrm{C}$ grown at $2.25 \%$ oxygen ratio compared to the other ones having the same thickness. As a result, it can be concluded that $2.25 \%$ oxygen ratio for $125 \mathrm{~nm}$ thick film includes more abundant peaks corresponding to strong vibrational modes of $\mathrm{VO}_{2}$ phase. As increasing $\mathrm{O}_{2}$ ratio from $2.25 \%$ to $3.00 \%$, the intensity of $\mathrm{V}_{2} \mathrm{O}_{5}$ phase increases while that of $\mathrm{VO}_{2}$ phase decreases. The Raman peak at $285 \mathrm{~cm}^{-1}$ is assigned to $\mathrm{V}_{2} \mathrm{O}_{5}$ phase of sample $\mathrm{B}$ [46]. Also, the broad peak at around $320 \mathrm{~cm}^{-1}$ could be belong to amorphous $\mathrm{V}_{2} \mathrm{O}_{5}$ [47]. For sample B, there is another broad peak at around $386 \mathrm{~cm}^{-1}$ which is shifted by $\sim 6 \mathrm{~cm}^{-1}$ compared to the Raman peak of sample A at $392 \mathrm{~cm}^{-1}$. This Raman shift may be related to chemical bond of the molecule. These results are supported by XRD analysis that when the oxygen gas ratio increases above $2.25 \%$, the percentage of $\mathrm{VO}_{2}$ decreases while $\mathrm{V}_{2} \mathrm{O}_{5}$ phase increases.

\subsection{Optical properties}

Transmittance spectra measured at room temperature and $80{ }^{\circ} \mathrm{C}$ of grown $\mathrm{VO}_{2}$ thin films (samples $\mathrm{B}, \mathrm{C}, \mathrm{D}$ and $\mathrm{E}$ ) grown under different $\mathrm{O}_{2}$ flow rates are shown in figure 5 . Due to higher thickness of sample A (see table 1), transmittance measurements of all samples are not comparable. Therefore, the transmission spectrum of sample A was not set in this graph. Due to phase transition, the transmittance of the

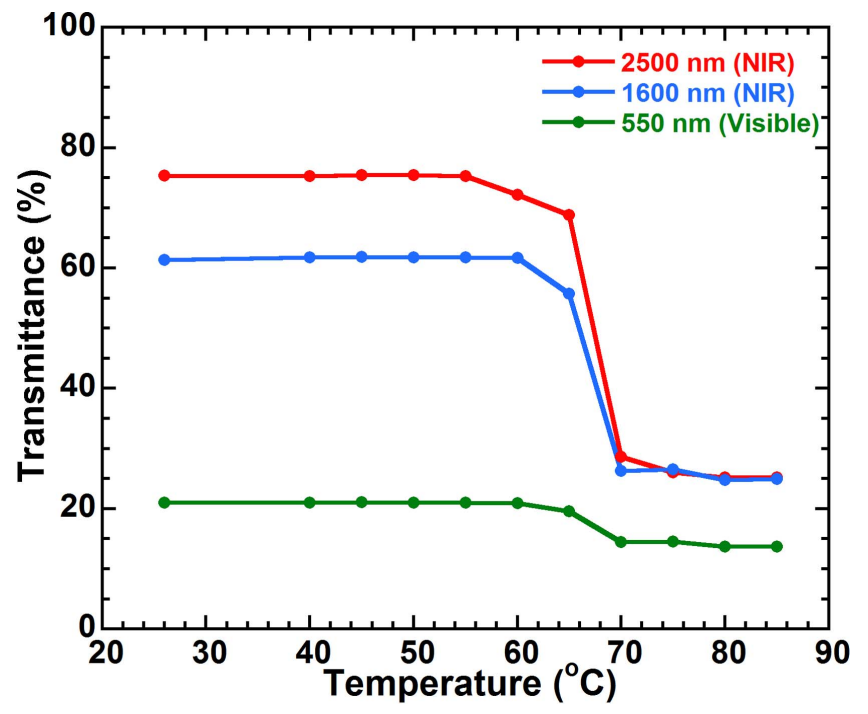

Figure 6. Temperature dependent transmission change is seen for various wavelengths in sample $\mathrm{C}$.

films decreases in near-IR region above MIT temperature. As it is clearly seen from the plots, $\mathrm{VO}_{2}$ thin films show high optical transmission in their insulating state, i.e. at room temperature, while low optical transmission in their metallic state in IR region above MIT temperature, namely $80^{\circ} \mathrm{C}$. Moreover, transmittance change was not observed in the film grown under $2.00 \% \mathrm{O}_{2}$ (sample B) flow rate. Since the as grown film is already in metallic phase, transmission at all temperatures, as expected, is low in IR region corresponding to the metallic case behavior. For grown thin films with $2.50 \%-3.00 \% \mathrm{O}_{2}$ ratio, the transmittance variation rates are almost the same, being around $8 \%-15 \%$. As it can be clearly seen in figure $5, \mathrm{VO}_{2}$ thin film grown under $2.25 \%$ oxygen ratio had the MIT, and showed the highest change in transmittance at IR region. Above transition temperature, $\mathrm{VO}_{2}$ has metallic phase resulting in an increment of electron concentration in the conduction band.

Figure 6 indicates the temperature dependent transmittance of deposited $125 \mathrm{~nm} \mathrm{VO}_{2}$ thin films grown under $2.25 \%$ oxygen flow ratio at the wavelengths of 1600 and $2500 \mathrm{~nm}$ for near infrared and $550 \mathrm{~nm}$ for visible regions. In visible region, transmittance varies $7 \%$ with temperature, and it is about $21 \%$ at low temperatures. In addition, transmittance change at MIT region is around $36 \%$ for $1600 \mathrm{~nm}$ and $50 \%$ for $2500 \mathrm{~nm}$ wavelength. It is concluded that transmittance of insulator $\mathrm{VO}_{2}$ phase is higher for $2500 \mathrm{~nm}$ than that of $1600 \mathrm{~nm}$ wavelength.

\subsection{Electrical properties}

It is known that mixed phases of vanadium oxide systems need to be optimized in terms of sputtering parameters to yield high quality pure $\mathrm{VO}_{2}$ phase. One of the most important properties that determine film quality is the resistivity drop at $T_{\text {MIT. }}$. It is indicated that the change in resistivity depends on uniformity of the film [48], strain, grain size and boundaries $[3,4,49]$. Epitaxially grown $\mathrm{VO}_{2}$ films are known to be the 


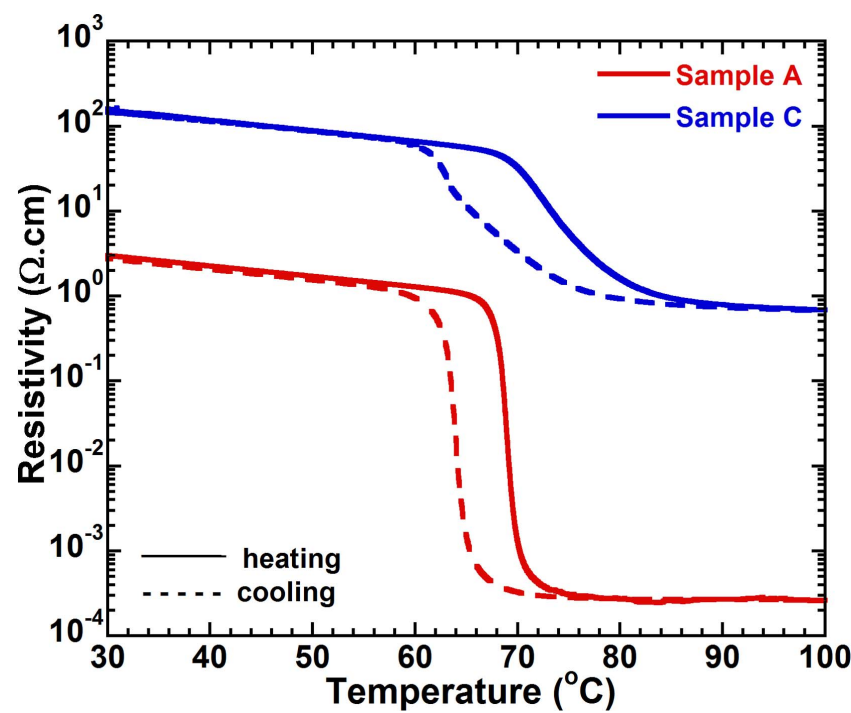

Figure 7. Thickness dependence of resistivity change across the MIT for sample A $(310 \mathrm{~nm})$ and $C(125 \mathrm{~nm})$ which are square samples.

best qualified films, and they exhibit resistivity changes an order of four at transition temperature [50]. Their hysteresis width of temperature changes from $0.5^{\circ} \mathrm{C}$ to $2{ }^{\circ} \mathrm{C}$ [51]. Recent studies support that resistivity changes in high quality $\mathrm{VO}_{2}$ films is about $10^{4}$ for magnetron sputter deposited $\mathrm{VO}_{2}$ films [26]. In our experiments, the sputtering conditions were optimized to obtain $\mathrm{VO}_{2}$ thin films having $10^{4}$ resistivity drop at $T_{\mathrm{MIT}}$.

Figure 7 shows the resistivity of these films in the measurement range between $30^{\circ} \mathrm{C}$ and $90^{\circ} \mathrm{C}$. The size of square samples was $4 \mathrm{~mm} \times 4 \mathrm{~mm}$. Note that the square samples were cut from large $\mathrm{VO}_{2}$ grown substrate, and silver electrodes were deposited. Square samples were not exposed to any e-beam process. It is clearly seen that the resistivity of sample A at transition temperature decreases more than $10^{4}$ of magnitude. $T_{\mathrm{MIT}}$ is about $68^{\circ} \mathrm{C}$, and the hysteresis loop width is about $4{ }^{\circ} \mathrm{C}$ for sample A, which are quite good values for DC sputtered $\mathrm{VO}_{2}$ thin films [52]. In addition, it is observed that resistivity change across transition decreases by a factor of $10^{2}$ for sample C. Therefore, it can be concluded that the films including high oxygen concentration with mixed phases show less resistivity change at transition temperature. The deposition time is an important factor to observe MIT in $\mathrm{VO}_{2}$. When deposition time decreases to $22.5 \mathrm{~min}$ from $45 \mathrm{~min}$, grown films are exposed to high temperature with $550{ }^{\circ} \mathrm{C}$ for less time. This leads to reduce the reactions of scattered $\mathrm{V}$ atoms with oxygen atoms. In this instance, instead of $\mathrm{VO}_{2}$, other vanadium oxide phases take place. Because of the reason, Sample B could not exhibit MIT at nearly $68^{\circ} \mathrm{C}$. Sample B exhibits more metallic properties compared to the other grown vanadium oxide thin films due to exposing lower reactions with oxygen atoms. For the other samples, in case of increasing oxygen concentration (from $2.00 \%$ to $3.00 \%$ ) with 22.5 min deposition time, it is necessary that new deposition parameters like deposition pressure should be determined in order to observe MIT. Under sample D and sample E fabrication conditions, there is more than enough oxygen present

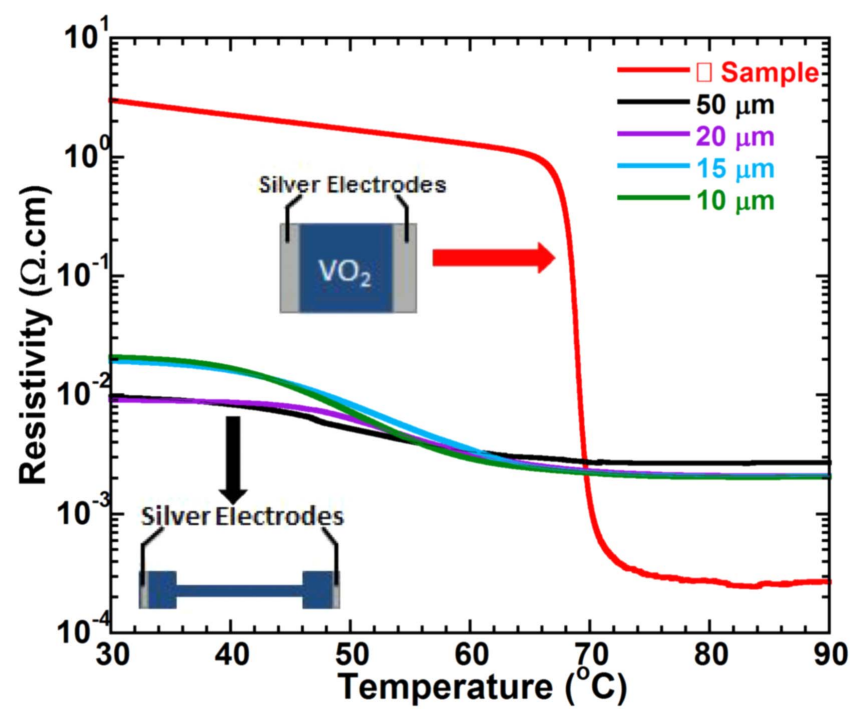

Figure 8. Temperature dependence of resistivity (during heating) for square sample A and the stripes with various widths.

to react with $\mathrm{V}$ atoms. The excess of oxygen concentration leads to coexist unexpected secondary phases and $\mathrm{VO}_{2}$ phase. Thus, these secondary phases prevent or reduce MIT in grown vanadium oxide thin film. Due to the excess of the oxygen concentration, sample D and sample E do not exhibit MIT properties.

Figure 8 shows temperature dependence of resistivity for a square sample and the e-beam lithography patterned $\mathrm{VO}_{2}$ stripes. Note that the square sample is not patterned and measured as grown. The square sample is shown as an inset picture of figure 8, whereas the optical microscopy and SEM images of stripes can be seen in figure 1 . The length of the stripes was $2.2 \mathrm{~mm}$ and the widths of the stripes were changed from 10 to $50 \mu \mathrm{m}$. Therefore, aspect ratios were ranging from 220 to 44 . It has been observed that the resistivity of $\mathrm{VO}_{2}$ stripes decreased down to around $10^{-2} \Omega \mathrm{cm}$ at room temperature (figure 8). It can be also seen that the $T_{\mathrm{MIT}}$ shifted to about $50^{\circ} \mathrm{C}$. On the other side, the resistivity drop was only one order for the stripes at $T_{\mathrm{MIT}}$. As a summary, when the electrical properties of the square sample are compared to those of stripes, three distinct changes occur: (i) the resistivity value at room temperature decreases, (ii) resistivity changes at MIT get smaller, (iii) $T_{\mathrm{MIT}}$ shifts to $50^{\circ} \mathrm{C}$ from $68^{\circ} \mathrm{C}$ which is getting closer to room temperature, and (iv) the resistivity value at room temperature increases. These variations could be related to the e-beam patterning processes of the stripes. We investigated the influence of soft bake, developer and hard bake on the electrical properties of $\mathrm{VO}_{2}$ films. However, there was not any change in electrical results for $\mathrm{VO}_{2}$. The stripes of $\mathrm{VO}_{2}$ films were exposed to electrons with $10 \mathrm{keV}$ energy during e-beam lithography process held around $1.3 \times 10^{-6}$ Torr vacuum. Under this circumstance, electron beam could affect the structure of grown $\mathrm{VO}_{2}$ thin film. During e-beam lithography process, applied electron current leads to local heating on the surface of the film. In case of taking place local heating in high vacuum ambiance, a number of oxygen might release from $\mathrm{VO}_{2}$ thin film. 
Therefore, the reduction in oxygen concentration of grown VO2 film leads to consist of secondary phase which are in metallic phase of vanadium oxide compounds. Since the electrons prefer low resistance paths, it is reasonable that we get low resistivity at room temperature for e-beam patterned samples. In contrary to this, the secondary phases increase the resistance above $T_{\mathrm{MIT}}$ for patterned samples. As a result, we observe distinct properties of $\mathrm{VO}_{2}$ stripes produced after e-beam lithography processes than those of square sample. Moreover, as we know from the literature studies, since the MIT in $\mathrm{V}_{2} \mathrm{O}_{3}$ and $\mathrm{V}_{6} \mathrm{O}_{13}$ occurs, respectively, at $-105^{\circ} \mathrm{C}$ [53] and $-123^{\circ} \mathrm{C}$ [54], they are in metallic phases of vanadium oxide at the temperatures of our measurement region. In order to create patterned $\mathrm{VO}_{2}$ structures, there are various methods, such as lift-off process [55]. Compared to their works which include lift-off method, we examined electron beam effect on $\mathrm{VO}_{2}$ thin film. In order to create patterned vanadium oxide stripes, $\mathrm{VO}_{2}$ thin film was shaped by electron beam lithography. In our works, during electron beam writing on $\mathrm{VO}_{2}$ thin film, the film was exposed to electron beam with $10 \mathrm{keV}$ energy. Our works show that electron beam lithography leads to decrease the change in resistivity of patterned stripes compared to $\mathrm{VO}_{2}$ thin film. In order to give shape to $\mathrm{VO}_{2}$ film, because of the negative effect of electron beam lithography, lift-off process could be better option for now. In this case, new research and studies will be required in order to prevent negative effect of electron beam lithography. Because electron beam lithography provides significant advantages in terms of its high resolution property for nanotechnology. Furthermore, SEM picture in figure 1(b) demonstrates large roughness of the sample. While the details of picture reveals grains as given in figure 2(a), figure 1(b) could be between figures 2(a) and (b) in terms of the surface morphology. So this change could be caused by e-beam influence on stripes.

\subsubsection{Raman analysis results of patterned vanadium oxide} stripes. Because of the nano-stripes, we are not able to look at XRD study to find crystal structure of patterned stripes. Furthermore, XPS studies cannot obtain local data from these stripes. On the other hand, we analyzed vanadium oxide stripes by confocal Raman spectroscopy, and Raman analysis results is shown in figure 9.

Due to strong resonance effect, in order to observe the Raman peaks at 192 and $222 \mathrm{~cm}^{-1}, 633 \mathrm{~nm}$ laser is better than $514 \mathrm{~nm}$ one. Because of this, in order to observe all phonon modes and prevent weak signals, $633 \mathrm{~nm}$ laser was used for Raman analysis of patterned samples. In figure 9, the vibration bands of $\mathrm{VO}_{2}$ were observed by the peaks at 192 , $222,260,306,337,386,442,497$ and $613 \mathrm{~cm}^{-1}$. These peaks are consistent with the literature [45]. After e-beam process, patterned vanadium oxide stripes (width range from 20 to $10 \mu \mathrm{m})$ were analyzed by Raman spectroscopy. As shown in figure 9, the peak at $192 \mathrm{~cm}^{-1}$ was observed at lower intensity compared to the patterned stripes. The intensity variation between the stripes and $\mathrm{VO}_{2}$ thin film for bands at $192 \mathrm{~cm}^{-1}$ may be due to differences in vanadium oxide crystal orientations. The Raman peak at $442 \mathrm{~cm}^{-1}$ which was

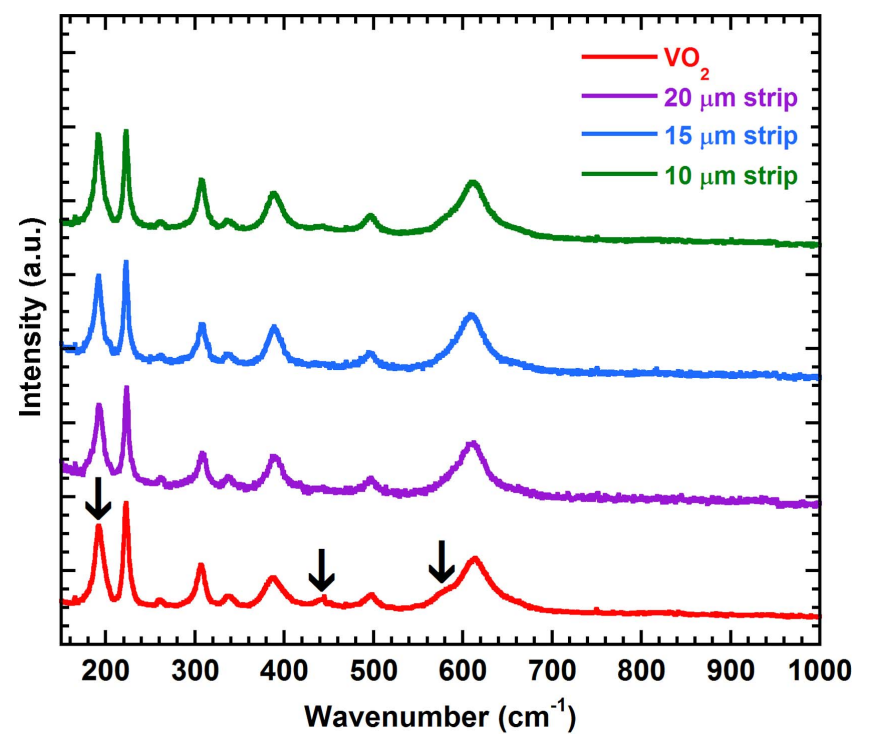

Figure 9. Raman spectrum of $\mathrm{VO}_{2}$ and patterned vanadium oxide stripes (width range from 20 to $10 \mu \mathrm{m}$ ).

observed for $\mathrm{VO}_{2}$ film was vanished for all patterned vanadium oxide stripes. According to Raman analysis of $\mathrm{VO}_{2}$ film, there is a shoulder located at around $580 \mathrm{~cm}^{-1}$. This shoulder was vanished in Raman analysis of patterned vanadium oxide stripes. These results show that not only variation of crystal orientation but also weaker crystalline properties occurred due to the e-beam exposure. Raman studies are also in agreement with the electrical measurements given in figure 8 . It can be seen that the resistivity drops in the stripes at room temperature support that the secondary phases occurred in e-beam patterned structures. Therefore, it can be concluded that the obtained crystal structure variations are caused by e-beam patterning of stripes.

\section{Conclusion}

In summary, we have obtained high quality DC magnetron sputtered $\mathrm{VO}_{2}$ thin films on c-cut sapphire substrate. Various oxygen concentrations were performed and optimized to obtain $\mathrm{VO}_{2}$ films with a sharp resistivity drop across MIT. The change in resistivity at transition temperature of $\mathrm{VO}_{2}$ thin film is around by a factor of $10^{4}$, and it is convenient for electrical switching applications. Moreover, the grown $\mathrm{VO}_{2}$ thin films exhibit nearly $50 \%$ transmission change in near-IR region, which is promising for optical applications, such as thermochromic windows.

The grown $\mathrm{VO}_{2}$ films having $10^{4}$ resistivity drop were used for the electrical characterization of patterned stripes. For these measurements, e-beam lithography and Ar ion etching processes were used for the purpose of patterning the grown $\mathrm{VO}_{2}$ films in the form of stripes. As a result, we have investigated the effect of e-beam patterning on MIT characteristics of $\mathrm{VO}_{2}$ films when the electrical characteristics of the stripes and square samples are compared. It is observed that $T_{\mathrm{MIT}}$ shifts close to room temperature after patterning the $\mathrm{VO}_{2}$ films by e-beam lithography. E-beam causes a change in oxygen concentration of grown $\mathrm{VO}_{2}$ 
thin film (figure 8), the metallic phase of vanadium oxide compounds becomes dominant. Secondary phases of $\mathrm{VO}_{x}$ might originate from low oxygen concentration due to local heating under high vacuum. Formed metallic phase of the secondary phase in $\mathrm{VO}_{x}$ causes a drop of resistivity of the film at room temperature while the degradation of ideal oxygen concentration leads to a decrease in the ratio of resistivity values (MIT rate) at $30{ }^{\circ} \mathrm{C}-90{ }^{\circ} \mathrm{C}$. Lastly, the change in resistivity of the $\mathrm{VO}_{2}$ stripes is an order of magnitude, and transition temperature shifts from $68{ }^{\circ} \mathrm{C}$ to $50{ }^{\circ} \mathrm{C}$. Shifting $T_{\mathrm{MIT}}$ to a closer region of room temperature might be important in terms of many applications, such as thermochromic windows and bolometers.

\section{Acknowledgments}

This research is partially supported by TUBITAK (The Scientific and Technological Research Council of Turkey) with the project number $113 \mathrm{~F} 349$ and partially by the University Research Foundation (BAP) with the project number of 2015IYTE-42. Additionally, we thank to Applied Quantum Research Center (AQUREC) of IZTECH for the research facilities offered us with this study.

\section{References}

[1] Balu R and Ashrit P V 2008 Appl. Phys. Lett. 9221904

[2] Gopalakrishnan G, Ruzmetov D and Ramanathan S 2009 J. Mater. Sci. 445345

[3] Nag J, Payzant E A, More K L and Haglund R F Jr 2011 Appl. Phys. Lett. 98251916

[4] Nagashima K, Yanagida T, Tanaka H and Kawai T 2007 J. Appl. Phys. 10126103

[5] Fillingham P J 1967 J. Appl. Phys. 384823

[6] Guiton B S, Gu Q, Prieto A L, Gudiksen M S, Park H and Amer J 2005 Chem. Soc 127498

[7] Liu K, Cheng C, Suh J, Tang-Kong R, Fu D, Lee S, Zhou J, Chua L O and Wu J 2014 Adv. Mater. 261746

[8] Yi X, Chen C, Liu L, Wang Y, Xiong B, Wang H and Chen S 2003 Infrared Phys. Technol. 44137

[9] Imada M, Fujimori A and Tokura Y 1998 Rev. Mod. Phys. 701039

[10] Donev E U, Lopez R, Feldman L C and Haglund R F 2009 Nano Lett. 9702

[11] Goodenough J B 1971 J. Solid State Chem. 3490

[12] Krammer A, Magrez A, Vitale W A, Jeanneret P, Guibert E, Whitlow H J, Ionescu A M and Schüler A 2017 J. Appl. Phys. 122045304

[13] Gupta A, Singhal R, Narayan J and Avasthi D K 2011 J. Mater. Res. 262901

[14] Wu J M and Liou L B 2011 J. Mater. Chem. 215499

[15] Jiang M, Cao X, Bao S, Zhou H and Jin P 2014 Thin Solid Films $\mathbf{5 6 2} 314$

[16] Yuce H 2015 MS Thesis Izmir Institute of Technology (http://hdl.handle.net/11147/4585)

[17] Ruzmetov D, Gopalakrishnan G, Deng J, Narayanamurti V and Ramanathan S 2009 J. Appl. Phys. 10683702

[18] Kato K, Song P K, Odaka H and Shigesato Y 2003 Japan. J. Appl. Phys. 426523

[19] Cui H N, Teixeira V, Meng L J, Wang R, Gao J Y and Fortunato E 2008 Thin Solid Films 5161484
[20] Dicken M J, Aydin K, Pryce I M, Sweatlock L A, Boyd E M, Walavalkar S and Atwater H A 2009 Opt. Express 1718330

[21] Chen C, Yi X, Zhao X and Xiong B 2001 Sensors Actuators A 90212

[22] Gauntt B D, Dickey E C and Horn M W 2009 J. Mater. Res. 241590

[23] Fieldhouse N, Pursel S M, Horn M W and Bharadwaja S 2009 J. Phys. D: Appl. Phys 42055408

[24] Alaboz H, Demirhan Y, Yuce H, Aygun G and Ozyuzer L 2017 Opt. Quantum Electron. 49238

[25] Stefanovich G, Pergament A and Stefanovich D 2000 J. Phys.: Condens. Matter 128837

[26] Ruzmetov D, Gopalakrishnan G, Ko C, Narayanamurti V and Ramanathan S 2010 J. Appl. Phys. 107114516

[27] Narayan J and Bhosle V 2006 J. Appl. Phys. 100103524

[28] Kim D and Kwok H 1994 Appl. Phys. Lett. 653188

[29] Maruyama T and Ikuta Y 1993 J. Mater. Sci. 285073

[30] Dagur P, Mane A U and Shivashankar S 2005 J. Cryst. Growth 2751223

[31] Mousavi M, Kompany A, Shahtahmasebi N and Bagheri-Mohagheghi M-M 2013 Phys. Scr. 886

[32] Yoon J, Kim H, Mun B S, Park C and Ju H 2016 J. Appl. Phys. 119124503

[33] Partlow D, Gurkovich S, Radford K and Denes L 1991 J. Appl. Phys. 70443

[34] Li S Y, Namura K, Suzuki M, Niklasson G A and Granqvist C G 2013 J. Appl. Phys. 114033516

[35] Kusano E, Theil J and Thornton J A 1988 J. Vac. Sci. Technol. A 61663

[36] Shigesato Y, Enomoto M and Odaka H 2000 Japan. J. Appl. Phys. 396016

[37] Youn D H, Kim H T, Chae B G, Hwang Y J, Lee J W, Maeng S L and Kang K Y 2004 J. Vac. Sci. Technol. A 22719

[38] Tuna O, Selamet Y, Aygun G and Ozyuzer L 2010 J. Phys. D: Appl. Phys 43055402

[39] Ozdemir M, Kurt M, Ozyuzer L and Aygun G 2016 Eur. Phys. J. Appl. Phys. 7530401

[40] Turkoglu F, Koseoglu H, Demirhan Y, Ozyuzer L, Preu S, Malzer S and Kadowaki K 2012 Supercond. Sci. Technol. 25 125004

[41] Demirhan Y, Saglam H, Turkoglu F, Alaboz H, Ozyuzer L, Miyakawa N and Kadowaki K 2015 Vacuum B 12089

[42] Zhang H, Wu Z, He Q and Jiang Y 2013 Appl. Surf. Sci. 277218

[43] Luo Y, Zhu L, Zhang Y, Pan S, Xu S, Liu M and Li G 2013 J. Appl. Phys. 113183520

[44] Zhu N-W, Hu M, Xia X-X, Wei X-Y and Liang J-R 2014 Chin. Phys. B 23048108

[45] Zhao Y, Lee J H, Zhu Y, Nazari M, Chen C, Wang H and Fan Z 2012 J. Appl. Phys. 111053533

[46] Piccirillo C, Binions R and Parkin I P 2007 Chem. Vapor Depos. 13145

[47] Öksüzoğlu R M, Bilgiç P, Yıldırım M and Deniz O 2013 Opt. Laser Technol. 48102

[48] Son L N, Tachiki T and Uchida T 2011 Japan. J. Appl. Phys. $\mathbf{5 0} 025803$

[49] Ruzmetov D, Zawilski K T, Narayanamurti V and Ramanathan S 2007 J. Appl. Phys. 102113715

[50] Tashman J W et al 2014 Appl. Phys. Lett. 104063104

[51] Berglund C and Guggenheim H 1969 Phys. Rev. 1851022

[52] Gurvitch M, Luryi S, Polyakov A and Shabalov A 2009 J. Appl. Phys. 106104504

[53] Wu C, Feng F and Xie Y 2013 Chem. Soc. Rev. 425157

[54] Eguchi R, Yokoya T, Kiss T, Ueda Y, Tajima H, Yamazaki J and Shin S 2002 Physica B 312600

[55] Yamin T, Havdala T and Sharoni A 2014 Mater. Res. Express 1046302 